\title{
Muscle fibre membrane lipid composition in musculus biceps femoris of pigs reared in indoor or outdoor systems
}

\author{
O. Ali ${ }^{1,5}$, Z. Petrási ${ }^{1}$, T. Donkó ${ }^{1}$, H. Fébel ${ }^{2}$, M. Mézes ${ }^{3}$ and A. Szabó ${ }^{1,4}$ \\ Hungarian University of Agriculture and Life Sciences, Institute of Physiology and Nutrition, \\ ${ }^{1}$ Department of Physiology and Animal Health, Kaposvár Campus, 7400 Kaposvár, Hungary \\ 2 Department of Nutrition and Nutrition Physiology, 2053, Herceghalom, Hungary \\ ${ }^{3}$ Department of Feed Safety, Gödöllő Campus, 2103 Gödöllő, Hungary \\ ${ }^{4}$ Department of Physiology and Animal Health, MTA-KE-SZIE Mycotoxins in the Food Chain Research Group, \\ Kaposvár Campus, 7400 Kaposvár, Hungary
}

KEY WORDS: body composition, cell membranes, fatty acids, outdoor, pigs, skeletal muscle

Received: 22 April 2021

Revised: 9 June 2021

Accepted: 22 June 2021

${ }^{5}$ Corresponding author:

e-mail: omeralfaroug.ali@gmail.com

\begin{abstract}
Two fundamentally different keeping systems, outdoor and indoor (10 weaned-pigs/system), were used with a quasi-identical feeding process. At $120 \mathrm{~kg}$ live body weight, animals underwent a computerized tomography scanning, during which musculus biceps femoris and blood samples were collected to determine the fatty acid (FA) profile of skeletal muscle phospholipids and plasma oxidative stability, respectively. The growth showed a fallback in the outdoor rearing system (another 8 days were needed) during the finishing stages. From the total body volume $\left(\mathrm{cm}^{3}\right)$, the muscle $(\%)$ increased and fat (\%) decreased in outdoor animals. The FA total saturation level, total monounsaturation level and thrombogenicity index were higher in muscular phospholipids. In contrast, proportional decreases in totals of polyunsaturation and omega-6 FAs, and in the unsaturation and peroxidation indices were detected. Among omega-3 FAs, C18:3n3 and C22:6n3 proportions were higher in outdoor pigs, and thus, the omega-6:omega-3 ratio declined. The outdoor rearing system did not influence the plasma antioxidant system. Overall, outdoor production altered the skeletal muscle fibre membrane FA profile and total body characteristics, but it compromised the pig growth.
\end{abstract}

\section{Introduction}

Intensive pig production may cause stress on the animals, which can deteriorate the carcass quality (Beattie et al., 2000). However, the perception of outdoor rearing (free-range with or without grazing and organic production) is well-known to be ethically preferred but challenging pigs with a vast range of environmental conditions influences the behaviour and performance of pigs. Therefore, the outdoor production system requires a high-quality management approach. Most consumers associ- ate the outdoor reareing of pigs with better taste and nutritional value of meat (Nilzén et al., 2001), although a few studies have reported deterioration in sensorial qualities (Enfält et al., 1997). The undesirable effects of outdoor and organic production on the back-fat thickness are evident, and highly depend on environmental conditions and dietary intake (Enfält et al., 1997; Andresen et al., 2001; Gustafson and Stern, 2003; Strudsholm and Hermansen, 2005; Lebret, 2008; White et al., 2013; Martino et al., 2014; Martínez-Miró et al., 2016). 
Outdoor systems necessitate specific genotypes suited to various climates, whereas a few genotypes perform well in outdoor systems (Guy et al., 2002). Indigenous genotypes are more tolerant to changes in the outdoor systems' environmental conditions (Tomažin et al., 2019) due to high immune-competence and adaptability to ecological conditions. Nowadays, indigenous genotypes have declined progressively due to selection (heterosis = hybrid vigour), an assortment of production and meat quality factors among pig genotypes (Bunter et al., 2008; Lemke et al., 2008). As pig breeding has developed rapidly, numerous studies have assessed the effects of the housing system on pig growth, carcass composition and meat quality. However, those studies provide inconclusive data and, in many cases, are contradictory (Olsson et al., 2003; Gentry et al., 2004; Lebret, 2008; Juska et al., 2013; Lebret et al., 2014). The argument is mainly attributed to the different investigation aims of studies and the environmental conditions (such as diet, temperature, humidity) in different regions.

Regardless of studies that assessed indoor and outdoor keeping methods, a few studies have investigated the impact of keeping methods on muscle lipids (Andrés et al., 2001; Nilzén et al., 2001; Hoffman et al., 2003; Strudsholm and Hermansen, 2005; Lebret, 2008; Parunović et al., 2012). Findings varied among studies, depending upon the investigated muscle, environmental conditions, access to forage and the intramuscular lipid fraction analyzed (triglycerides, phospholipids or total lipids). The predominant forms of muscle lipids are triglycerides and phospholipids, and they largely differ in fatty acid (FA) profiles. Triglycerides (prominent role in energy supply and storage) are considered to be rich in 16-18 carbon chains of both saturated FAs (SFA) and monounsaturated FAs (MUFA). On the other hand, phospholipids are richer in long-chain polyunsaturated FAs (PUFA) than triglycerides (Zhang et al., 2009). Cellular homeostasis sustainability is the primary role of phospholipid FAs since they are vital constituents of membranes and the $\mathrm{C} 20 \mathrm{n}-3$ and n-6 FAs act as precursors for eicosanoid synthesis. Once triglycerides' prominent role is energy supply/storage, their FA profile is likewise determined by the diet (Högberg et al., 2003). Investigating modifications in phospholipid FA composition leads to new information that partly aids in the understanding of numerous aspects of cellular metabolism. The musculus biceps femoris is a fasttwitch muscle that plays a vital role in locomotion and exercise. This muscle has been intensively studied (besides $m$. longissimus dorsi) and is widely used in ham production (by the food industry).
This study aimed to establish if and how outdoor keeping (without forage supply) of a commercial, non-indigenous pig genotype (Danbred, produced by the genomic selection process) influences the FA composition of $m$. biceps femoris phospholipids. Also, we investigated the growth potential differences between indoor and outdoor rearing systems without access to forage.

\section{Material and methods}

\section{Animals, experimental design and ethical issues}

The experiment was approved by the Animal Experimentation Ethics Committee of Kaposvár University, as allowed by the Somogy County Animal Health and Food Control Authority (allowance no.: SOI/31/26-11/2014).

Twenty Danbred genotype mixed sex $(50 \%$ castrated males, $50 \%$ females) pigs at the same age (75 days) and body weight ( $30 \mathrm{~kg}$ ) were enrolled in the study. The study lasted from June to September (76 and 84 days for indoor and outdoor animals, respectively), with ambient temperatures ranged (from min. 8 to $\max .32{ }^{\circ} \mathrm{C}$ ) and an average of $21{ }^{\circ} \mathrm{C}$. Animals were kept in two fundamentally different systems (10 animals/system) at a farm in Hungary. The first system (indoor) was according to a widely used intensive, closed system, i.e. a closed barn, self-feeders and drinkers, tri-phasic feeding with diet offered ad libitum. The rearing system was a Big Dutchman technology with a keeping area of $6 \times 4 \times 2.5 \mathrm{~m}\left(2.4 \mathrm{~m}^{2} / \mathrm{animal}\right)$. Secondly, the non-intensive system (outdoor) was realized in a growing pig keeping mobile barn system (two mobile shaded barns, for each dimension of $5 \times$ $2.4 \times 2 \mathrm{~m} / 5$ animals) with free access to unshaded (direct sunlight) land, where natural feed was not available (main characteristics of each system are presented in Table 1). As the same for the indoor system, tri-phasic feeding and drinking water were

Table 1. The main differences between indoor and outdoor conditions

\begin{tabular}{lll}
\hline Condition & Indoor system & Outdoor system \\
\hline System type & $\begin{array}{l}\text { Big Dutchman } \\
\text { technology }\end{array}$ & mobile barn \\
& system \\
Keeping area & $24 \mathrm{~m}^{2}$ & $24 \mathrm{~m}^{2}$ \\
Shade & present & present \\
Free access to outside barn & not present & present \\
Natural feed supplement & not present & not present \\
Sunlight exposure & not present & available \\
Diet phases & tri-phasic feeding & tri-phasic feeding \\
Feeding and drinking water & ad libitum & ad libitum \\
\hline
\end{tabular}


offered ad libitum. Ingredients used in diets were maize, wheat, extracted soyabean, barley, distiller's dried grains with solubles (DDGS), rapeseed, sunflower (ground), $\mathrm{CaCO}_{3}, \mathrm{NaCl}$ and $\mathrm{MgO}_{2}$. The diet formulation and optimization was performed by Bonafarm-Bábolna Takarmány Kft. (B.-B. Feed Ltd., Bábolna, Hungary). Nutritive values of diets are presented in Table 2, whereas the fattening diet (phase III) was analyzed also for FA composition.

Table 2. Nutritive values of diets (phases I-III) and fatty acid composition of the fattening diet (phase III)

\begin{tabular}{lccc}
\hline & \multicolumn{3}{l}{ Nutritional values } \\
\cline { 2 - 4 } Component & phase I & phase II & phase III \\
& $10-30 \mathrm{~kg}$ & $30-60 \mathrm{~kg}$ & $60-120 \mathrm{~kg}$ \\
\hline \% of DM & & \\
crude protein & 19.9 & 17.4 & 15 \\
crude fat & 4.8 & 3.3 & 3.1 \\
crude fibre & 4 & 5.2 & 4 \\
crude ash & 5.9 & 5.4 & 4.2 \\
Ca & 0.8 & 0.66 & 0.55 \\
available P & 0.42 & 0.34 & 0.4 \\
Fatty acid, \% of all fatty acid methyl esters & \\
C12:0 & & & 0.06 \\
C14:0 & & 0.33 \\
C15:0 & & 0.09 \\
C16:0 & & 18.0 \\
C17:0 & & 0.20 \\
C18:0 & & 9.67 \\
C20:0 & & 0.69 \\
C22:0 & & 0.86 \\
C24:0 & & 0.97 \\
C16:1n7 & & 0.82 \\
C18:1n9 & & 20.1 \\
C20:1n9 & & 0.63 \\
C18:2n6 & & 43.2 \\
C18:3n6 & & 0.13 \\
C20:2n6 & & 0.11 \\
C18:3n3 & & 4.15 \\
C20:5n3 & & 0.02 \\
\hline DM - $1 y$ mate & &
\end{tabular}

DM - dry matter

Animals were not sacrificed for sampling at the end of the experiment. The muscle and blood samples were taken at precisely $120 \mathrm{~kg}$ body weight when animals underwent computerized tomographic scanning under anaesthesia (isoflurane $+\mathrm{O}_{2}$, tidal volume: $5-10 \mathrm{ml} / \mathrm{kg}$, flow $21 / \mathrm{min} \mathrm{O}_{2}, 2 \mathrm{vol} \%$ isoflurane). The biopsy was performed by a scalpel blade and tissue forceps from the fast-twitch m. biceps femoris (about $0.5 \mathrm{~g}$ ), and samples were flash-frozen in liquid nitrogen. Blood samples were taken into heparinized (Li-heparinate) Vacutainer tubes (BD, Fisher Scientific UK Ltd, Leicestershire, UK) and centrifuged immediately at $1500 \mathrm{~g}$ for $10 \mathrm{~min}$. Plasma was stored frozen, as well as muscle samples, until subsequent analysis.

\section{Growth and body trait parameters}

The body weight of all animals was measured weekly. At exactly 30, 60, 90, 120 live body weights, animal ages were recorded. The body length at the specified body weights were calculated from the computer tomography scan-topograms (Siemens Somatom Definition Flash Scanner, Siemens, Erlangen, Germany). Also, the body trait parameters (percentages of muscle, fat and bone from the whole volume $\left.\left(\mathrm{cm}^{3}\right)\right)$ were assessed from the scans (Figure 1) using a simple threshold segmentation method on the entire body (Skjervold et al., 1981).
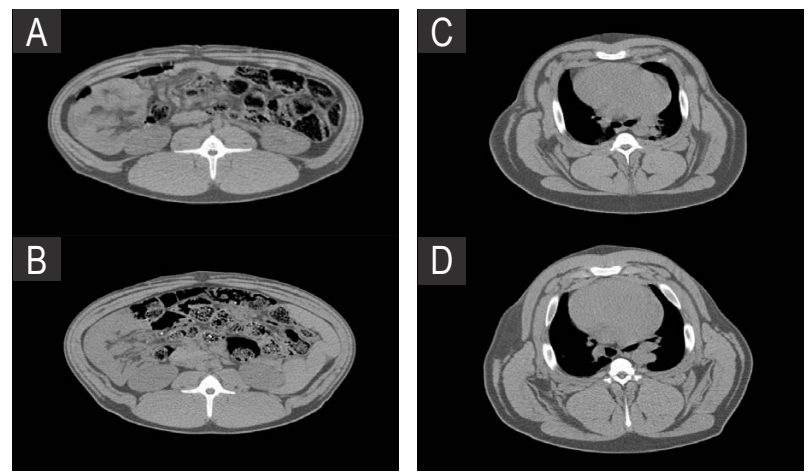

Figure 1. Illustration of the cross-sectional computer tomography scans at exact anatomical locations for the indoor and outdoor pigs at $120 \mathrm{~kg}$ body weights, in which $(A)$ and $(B)$ were made at the level of tracheal bifurcation for indoor and outdoor animals, respectively, and (C) and (D) were made at the level of the $1^{\text {st }}$ lumbar vertebra for indoor and outdoor animals, respectively.

\section{Fat extraction and muscle phospholipid fatty acid composition}

For each sample, the whole tissue (about $0.5 \mathrm{~g}$ ) was homogenized (IKA T25 Digital Ultra Turrax, Staufen, Germany) in a 20 -fold volume of chloroform:methanol (2:1 vol:vol) and total lipid content was extracted (Folch et al., 1957). Solvents were ultrapure-grade (Sigma-Aldrich, St. Louis, MO, USA) and $0.01 \% \mathrm{w}: \mathrm{v}$ butylated hydroxytoluene was added to prevent FA oxidation. In the frame of lipid fractionation, extracted total lipids were transferred to glass chromatographic columns containing $300 \mathrm{mg}$ of silica gel (230-400 mesh) for $10 \mathrm{mg}$ of lipids (Leray et al., 1997). Neutral lipids were eluted with $10 \mathrm{ml}$ of chloroform for the above fat amount, then $15 \mathrm{ml}$ of acetone:methanol (9:1 vol:vol) was added, while $10 \mathrm{ml}$ of pure methanol eluted the total phospholipids. This latter fraction was evaporated to dryness under a nitrogen stream and was transmethylated with a base-catalyzed $\mathrm{NaOCH}_{3}$ method (Christie, 1982). FAmethyl-esters were extracted into $300 \mu 1$ ultrapure $n$-hexane for gas chromatography (GC). The latter was performed on a Shimadzu 2010 apparatus (AOC 20i automatic injector; Shimadzu, 
Kyoto, Japan) equipped with a Phenomenex Zebron ZB-WAX capillary GC column $(30 \mathrm{~m} \times 0.25 \mathrm{~mm}$ ID, $0.25 \mu \mathrm{m}$ film, Phenomenex Inc., Torrance, CA, USA) and a mass spectrometry (MS) detector. Characteristic operating conditions were: injector temperature: $270{ }^{\circ} \mathrm{C}$; detector temperature: $300{ }^{\circ} \mathrm{C}$; helium flow: $28 \mathrm{~cm} / \mathrm{sec}$. The oven temperature was graded: from 80 to $205^{\circ} \mathrm{C}: 2.5^{\circ} \mathrm{C} / \mathrm{min}, 5 \mathrm{~min}$ at $205^{\circ} \mathrm{C}$, from 205 to $250{ }^{\circ} \mathrm{C}: 10^{\circ} \mathrm{C} / \mathrm{min}$ and $5 \mathrm{~min}$ at $210^{\circ} \mathrm{C}$. The makeup gas was nitrogen. An authentic external FA methyl ester standard (37 Component FAME Mix, Cat No: CRM47885; Sigma-Aldrich, St. Louis, MO, USA) was used to identify individual FAs. FA results were expressed as the weight $\%$ of total FA-methyl esters.

The unsaturation index (UI), peroxidation index (PI) and average chain length (ACL) were calculated based on the empirical measurements of Hung et al. (2018):

$\mathrm{UI}=(\Sigma$ Monoenoic $\times 1)+(\Sigma$ Dienoic $\times 2)+$ $(\Sigma$ Trienoic $\times 3)+(\Sigma$ Tetraenoic $\times 4)+(\Sigma$ Pentaenoic $\times$

$$
5)+(\Sigma \text { Hexaenoic } \times 6) \text {; }
$$

$\mathrm{PI}=(0.025 \times \Sigma$ Monoenoic $)+(1 \times \Sigma$ Dienoic $)+(2 \times$ $\Sigma$ Trienoic $)+(4 \times \Sigma$ Tetraenoic $)+(6 \times \Sigma$ Pentaenoic $)+$ $(8 \times \Sigma$ Hexaenoic $)$;

$$
\mathrm{ACL}=\left(\Sigma \text { Total } \mathrm{Cn}_{i} \mathrm{FA} \times \mathrm{n}_{i}\right),
$$

where: $\mathrm{n}$ - carbon atom number.

The atherogenic index (AI) and thrombogenicity index (TI) were calculated according to the Ulbricht and Southgate (1991) equations:

$\mathrm{AI}=[\mathrm{C} 12: 0+(4 \times \mathrm{C} 14: 0)+\mathrm{C} 16: 0] /[\Sigma$ omega- 6 FA + omega-3 FA + MUFA];

$\mathrm{TI}=[\mathrm{C} 14: 0+\mathrm{C} 16: 0+\mathrm{C} 18: 0] /[(0.5 \times \mathrm{MUFA})+$ $(0.5 \times \Sigma$ omega- 6 FA $)+(3 \times \Sigma$ omega- 3 FA $)+$ omega-3 FA / omega-6 FA].

Hypocholesterolemic to hypercholesterolemic ratio $(\mathrm{h} / \mathrm{H})$ was calculated according to the Fernández et al. (2007) formula:

$\mathrm{h} / \mathrm{H}=(\mathrm{C} 18: 1+\mathrm{C} 18: 2+\mathrm{C} 18: 3+\mathrm{C} 20: 3+\mathrm{C} 20: 4+$ $\mathrm{C} 20: 5+\mathrm{C} 22: 4+\mathrm{C} 22: 5+\mathrm{C} 22: 6) /(\mathrm{C} 14: 0+\mathrm{C} 16: 0)$.

\section{Assessment of plasma antioxidant capacity and lipid peroxidation}

For the determination of plasma antioxidant capacity, samples were stored at $-80^{\circ} \mathrm{C}$, respectively, until analyzed. Lipid peroxidation was determined by quantifying malondialdehyde equivalent (MDA eq.) levels by the 2-thiobarbituric acid method (Botsoglou et al., 1994). Among the components of the antioxidant system, the concentration of reduced glutathione (GSH) was measured by the method of Rahman et al. (2006) and the activity of glutathione peroxidase (GSH-Px) according to Lawrence and
Burk (1978). GSH concentration and GSH-Px activity were calculated on a protein content basis, determined by the biuret method in the blood plasma (Weichselbaum, 1946).

\section{Statistical analysis}

An independent sample t-test with an IBM SPSS Statistics for Windows software, ver. 20 (2012; IBM, Armonk, NY, USA), was used to compare group meanings of muscle phospholipid FAs, antioxidants, age, and computer tomography scan based body trait parameters (body length, muscle $\%$, bone $\%$ and fat \%). A probability of $(P<0.05)$ was applied to statements of significance.

\section{Results}

\section{Growth and body trait parameters}

During the study period, no mortality was detected. From the computer tomography scans (i.e. topograms), no difference was observed in the calculated body length at the exact body weights, as shown in Table 3. The age required to reach the exact, pre-defined body weights were significantly different at 90 and $120 \mathrm{~kg}$ body weights (Table 3 ). In the outdoor system, pigs required more days (+8 days) to reach 90 and $120 \mathrm{~kg}$ body weights.

Table 3. The pig performance parameters (body length and age) for different phases of the study $(30,60,90$ and $120 \mathrm{~kg}$ body weights and

\begin{tabular}{|c|c|c|c|c|c|c|c|}
\hline \multirow{2}{*}{ Indices } & \multicolumn{3}{|c|}{ Indoor system } & \multicolumn{3}{|c|}{ Outdoor system } & \multirow{2}{*}{$P$-value } \\
\hline & mean & \pm & SEM & mean & \pm & SEM & \\
\hline \multicolumn{8}{|l|}{ Body length, $\mathrm{cm}$} \\
\hline BL gained & 47.8 & \pm & 2.13 & 47.5 & \pm & 3.23 & 0.938 \\
\hline $30 \mathrm{~kg}$ & 74.6 & \pm & 1.60 & 75.1 & \pm & 0.65 & 0.734 \\
\hline $60 \mathrm{~kg}$ & 99.3 & \pm & 2.22 & 98.3 & \pm & 2.32 & 0.753 \\
\hline $90 \mathrm{~kg}$ & 112 & \pm & 1.73 & 111 & \pm & 1.55 & 0.651 \\
\hline $120 \mathrm{~kg}$ & 122 & \pm & 1.75 & 122 & \pm & 3.03 & 0.907 \\
\hline \multicolumn{8}{|l|}{ Age, days } \\
\hline study length & 76.0 & \pm & 0.00 & 84.0 & \pm & 3.72 & 0.044 \\
\hline $30 \mathrm{~kg}$ & 76.0 & \pm & 0.00 & 76.0 & \pm & 0.00 & 1.000 \\
\hline $60 \mathrm{~kg}$ & 108 & \pm & 2.53 & 119 & \pm & 5.11 & 0.060 \\
\hline $90 \mathrm{~kg}$ & 132 & \pm & 1.64 & 141 & \pm & 5.01 & 0.038 \\
\hline $120 \mathrm{~kg}$ & 152 & \pm & 0.00 & 160 & \pm & 3.72 & 0.044 \\
\hline
\end{tabular}
overall) of the two examined rearing systems (10 pigs/group)

$\mathrm{BL}$ - body length; SEM - standard error of mean

The body composition results are presented in Table 4. At $120 \mathrm{~kg}$ body weight, pigs reared in the outdoor system have shown higher muscle and bone percentages than indoor animals. In contrast, fat (\%) was more pronounced in indoor animals than outdoor animals. 
Table 4. The body trait parameters in percentage (\%), as calculated from the whole body volume $\left(\mathrm{cm}^{3}\right)$ determined from the computer tomography scans at $120 \mathrm{~kg}$ body weight (10 pigs/group)

\begin{tabular}{|c|c|c|c|c|c|c|c|}
\hline \multirow{2}{*}{ Indices } & \multicolumn{3}{|c|}{ Indoor system } & \multicolumn{3}{|c|}{ Outdoor system } & \multirow{2}{*}{$P$-value } \\
\hline & mean & \pm & SEM & mean & \pm & SEM & \\
\hline Fat, \% & 30.7 & - & 0.91 & 25.6 & \pm & 0.99 & 002 \\
\hline Muscle, $\%$ & 48.2 & \pm & 0.83 & 52.6 & \pm & 0.93 & 0.003 \\
\hline Bone, $\%$ & 4.85 & \pm & 0.11 & 5.44 & \pm & 0.17 & 0.011 \\
\hline
\end{tabular}

SEM - standard error of mean

Table 5. Effect of rearing systems on phospholipid fatty acid profile of musculus biceps femoris of pigs (10 pigs/group)

\begin{tabular}{|c|c|c|c|c|c|}
\hline \multirow{2}{*}{ Indices } & \multicolumn{2}{|c|}{ Indoor system } & \multicolumn{2}{|c|}{ Outdoor system } & \multirow[b]{2}{*}{$P$-value } \\
\hline & mean & \pm SEM & mean & \pm SEM & \\
\hline \multicolumn{6}{|c|}{ Fatty acid, $\%$ of all fatty acid methyl esters } \\
\hline $\mathrm{C} 14: 0$ & 0.16 & \pm 0.01 & 0.19 & \pm 0.01 & 0.035 \\
\hline C15:0 & 0.11 & \pm 0.01 & 0.18 & \pm 0.02 & 002 \\
\hline $\mathrm{C} 16: 0$ & 20.9 & \pm 0.32 & 26.4 & \pm 0.95 & .000 \\
\hline C16:1n7 & 0.61 & \pm 0.08 & 1.15 & \pm 0.05 & .000 \\
\hline $\mathrm{C} 17: 0$ & 0.37 & \pm 0.02 & 0.64 & \pm 0.06 & .002 \\
\hline C18:0 & 16.4 & \pm 0.47 & 15.1 & \pm 0.46 & 0.069 \\
\hline C18 & 9.82 & \pm 0.34 & 13.5 & \pm 0.58 & .000 \\
\hline C18 & 33.7 & \pm 0.52 & 28.8 & \pm 0.67 & .000 \\
\hline $\mathrm{C} 18$ & 0.27 & \pm 0.02 & 0.32 & \pm 0.03 & .104 \\
\hline C18 & & \pm & & \pm 0.03 & .020 \\
\hline $\mathrm{C} 20$ & 0.07 & \pm & 0.05 & \pm 0.01 & 179 \\
\hline C & 0.14 & \pm 0 & 0.13 & \pm 0.01 & .479 \\
\hline $\mathrm{C} 2$ & 0 & \pm 0 & 0.43 & \pm 0.01 & 0.836 \\
\hline $\mathrm{C} 20$ & & \pm 0 & & \pm 0.10 & .440 \\
\hline $\mathrm{C} 20$ & 13.2 & \pm 0 & 9.30 & \pm 1.06 & 0.006 \\
\hline $\mathrm{C} 2$ & 0.06 & \pm 0.01 & 03 & \pm 0.00 & 0.004 \\
\hline C20: & & \pm 0.02 & 0.38 & \pm 0.06 & .081 \\
\hline $\mathrm{C} 2$ & & \pm & 04 & \pm 0.01 & .529 \\
\hline & & \pm 0 & 1.11 & \pm 0.16 & 0.071 \\
\hline & & \pm 0 & 0.67 & \pm 0.12 & .049 \\
\hline $\mathrm{C} 24: 0$ & 0.02 & \pm 0 & 0.04 & \pm 0.03 & .578 \\
\hline SFA & 38.1 & \pm 0.59 & 42.6 & \pm 1.36 & 0.011 \\
\hline UFA & 61.9 & \pm 0.59 & 57.4 & \pm 1.36 & 0.011 \\
\hline MUF & 10.6 & \pm 0.40 & 14.8 & \pm 0.59 & 0.000 \\
\hline PUFA & 51.4 & \pm 0.48 & 42.6 & \pm 1.91 & 0.002 \\
\hline omega & 48.5 & \pm 0.45 & 39.7 & \pm 1.66 & 0.001 \\
\hline omega-3 FAs & 2.41 & \pm 0.11 & 2.52 & \pm 0.28 & 0.712 \\
\hline odd chain & 0.48 & \pm 0.03 & 0.82 & \pm 0.07 & 0.001 \\
\hline Omega-6:omega-3 ratio & 20.5 & \pm 0.96 & 16.9 & \pm 1.51 & 0.043 \\
\hline Unsaturation index & 148 & \pm 1.42 & 128 & \pm 6.24 & 0.001 \\
\hline Peroxidation index & 105 & \pm 1.50 & 85.0 & \pm 6.54 & 0.017 \\
\hline Average chain length & 17.9 & \pm 0.01 & 17.7 & \pm 0.05 & 0.004 \\
\hline Atherogenic index & 0.35 & \pm 0.01 & 0.48 & \pm 0.03 & 0.002 \\
\hline Thrombogenicity index & 0.30 & \pm 0.01 & 0.32 & \pm 0.01 & 0.215 \\
\hline $\mathrm{h} / \mathrm{H}$ & 3.74 & \pm 0.14 & 3.73 & \pm 0.19 & 0.946 \\
\hline
\end{tabular}

SFA - saturated fatty acid, UFA - unsaturated fatty acid, MUFA - monounsaturated fatty acids, PUFA - polyunsaturated fatty acid, $\mathrm{h} / \mathrm{H}$ - hypocholesterolemic to hypercholesterolemic ratio; SEM - standard error of mean

\section{Muscle phospholipids fatty acid composition}

Fatty acids of the muscular cell phospholipids are presented in Table 5. The results revealed an increase in total saturation in the samples of the animals kept in the outdoor system. SFAs, namely palmitic, heptadecanoic, margaric and myristic acids (C16:0, C17:0, C15:0 and C14:0, respectively), were significantly higher in the outdoor reared pigs. For unsaturated FA(UFA), outdoor pigs had a markedly higher proportion of MUFAs than those kept indoors, particularly that of palmitoleic $(\mathrm{C} 16: 1 \mathrm{n} 7)$ and oleic acids (C18:1n9). Among PUFAs, linoleic acid (C18:2n6, LA) was the most abundant acid in both systems, followed by arachidonic acid (20:4n6). Both FAs proportions were statistically lower in the outdoor system. Except for linoleic and arachidonic acids, no difference was observed in omega-6 FAs. In omega-3 FAs, remarkable increases were recorded for docosahexaenoic acid (C22:6n3, DHA) and $\alpha$-linolenic acid (C18:3n3, ALA) proportions in pigs reared in the outdoor system. In contrast, eicosatrienoic acid (C20:3n3) was statistically higher in pigs from the indoor system. Overall, total unsaturation decreased significantly in the outdoor system, alongside the decrease in total PUFA, total sum of omega-6 FAs, the omega-6:omega-3 ratio, UI, PI and ACL. In contrast, the total MUFA concentration and AI were increased. Although the outdoor system altered some omega-3 FAs, the total sum of omega-3 FAs was not influenced. Similarly, the TI and $\mathrm{h} / \mathrm{H}$ indices were unaltered.

\section{Plasma antioxidants and the peroxidation biomarker}

The plasma MDA eq. and GSH concentrations and GSH-Px activity were measured to assess lipid peroxidation and antioxidant enzyme activities. None of the three examined parameters did significantly differ between the rearing systems (Table 6).

Table 6. Effect of rearing methods on plasma antioxidant and oxidative parameters of pig (10 pigs/group)

\begin{tabular}{|c|c|c|c|}
\hline \multirow{2}{*}{ Indices } & Indoor system & Outdoor system & \multirow{2}{*}{$P$-value } \\
\hline & mean \pm SEM & mean \pm SEM & \\
\hline tein & $2.29 \pm 0.10$ & $2.39 \pm 0.21$ & 0.698 \\
\hline GSH-P & $2.54 \pm 0.10$ & $2.93 \pm 0.29$ & 0.251 \\
\hline MDA eq., nmol/g & $9.32 \pm 0.34$ & $8.65 \pm 0.23$ & 0.113 \\
\hline
\end{tabular}

GSH - glutathione; GSH-Px - glutathione peroxidase; MDA eq. malondialdehyde equivalent; SEM - standard error of mean

\section{Discussion}

The present study approach determines the impact of an outdoor keeping system without extra feed supplementation on the modern pig genotype (namely the Danbred) potential growth, body composition, and possible cellular conditions through investigating the $m$. biceps femoris membrane lipids. 
However, according to the animal ethics protocol, animals were not sacrificed; therefore, no meat quality test was determined.

\section{Animal performance and body composition parameters}

Once animals' initial weight and age were similar, the extended period (more 8 days) in the outdoor system is a keeping method effect. Earlier studies investigated outdoor system impact on pigs. Lebret et al. (2014), Parunović et al. (2012), Patton et al. (2008), Strudsholm and Hermansen (2005), Bee et al. (2004), Hoffman et al. (2003), Enfält et al. (1997) and Sather et al. (1997) have shown a similar attribute. In contrast, Gentry et al. (2004) have documented the body weight increase in outdoor pigs. Most of these studies have linked the decrease in body weight gain of the outdoor system with the energetic demand from exercise and thermoregulation. In the design of Gentry et al. (2004), pigs were kept under the outdoor system with unlimited access to alfalfa pasture $\left(212 \mathrm{~m}^{2} / \mathrm{pig}\right)$, which was not in our case; only the complete diet was available. Therefore, two circumstances may reveal the finding of Gentry et al. (2004), either additional diet source was consumed (alfalfa) and/or less feed waste occurred in outdoor reared animals. From our perspective, less feed waste is not firmly possible, especially while the diet was fed ad libitum.

Kozera et al. (2016) reported no significant difference when pigs were kept indoors with and without free access to outdoor runs. In our design, animals were fully kept in the outdoor system during the entire study period, in which we expect more physical activity (more standing than lying down), postulating high nutritional requirements. In the present study, the average daily body weight gain was 1055 and $970 \mathrm{~g} /$ day for indoor and outdoor animals, respectively $(P<0.05$, data not shown). Those values are higher than those of Kozera et al. (2016), Karpiesiuk and Falkowski (2008) and Hoffman et al. (2003), who have reported 740, 727 and $725 \mathrm{~g} /$ day, respectively. The genetic characteristics of pigs are most likely responsible for the wide range of daily gains in body weight. We used the Danbred genotype to represent a non-indigenous meat-type hybrid, which expressed a typical average daily body gain similar to Maribo et al. $(2018 ; 1059 \mathrm{~g} / \mathrm{day})$.

Up to date, no clear outcome on the effect of the rearing system on pig body composition due to a variety of genotypes, feeding content and level, and housing condition has been presented (Lebret, 2008). Indigenous genotypes are more suitable to cope with outdoor environmental conditions than modern genotypes. In the present study, the outdoor system resulted in more muscles and bones, while less fat was recorded. Despite our approach investigated the total body fat and did not focus on intramuscular fat, in a few studies the decrease in intramuscular fat or more lean meat percentage in outdoor pigs was reported (Enfält et al., 1997; Sather et al., 1997; Hoffman et al., 2003; Urbańczyk et al., 2005; Strudsholm and Hermansen, 2005; Patton et al., 2008; Parunović et al., 2012; Juska et al., 2013; Lebret et al., 2014). The adipose tissue plays many roles in thermoregulation and energy supply/storage, indirectly referring to less fat volume in pigs kept in the outdoor system. Noteworthy, the phospholipid omega-6:omega-3 ratio was decreased in the outdoor system, postulating alteration in their derivatives and mediators that possibly alter fat-protein deposition and/or the sarcomeres development.

\section{Muscle phospholipids fatty acid composition}

In the current approach, the $m$. biceps femoris was chosen due to our presumption that it is essential during exercise. In this study, high proportions of myristic and palmitic acids were observed, which was consistent with the earlier report of Parunović et al. (2012) on total lipids from outdoor Mangalitza pig muscle ( $m$. longissimus dorsi). In contrast, for palmitic acid, a recent study by Dostálová et al. (2020) has presented a contradictory finding in the total fat of $m$. longissimus lumborum from pigs reared under an outdoor system with unlimited pasture access. Myristic and palmitic acids can acylate different proteins (Rioux, 2016); thus, high occupations might occur to enforce the protein acylation process. Those two saturated FAs are associated with more rigid muscle fibre membranes, a mechanism to tolerate stressors. Independently of their source/origin (diet or de novo biosynthesis), their influential presence in membrane lipids increased the total saturation level by $4.5 \%$. This finding agrees with the earlier report of Andrés et al. (2001) concerning $m$. tibialis cranialis. SFAs are known to lack a double bond, referring to less sensitivity towards oxidation. As a result, we hypothesize that elevated total saturation levels in the phospholipids of outdoor animals may provide a significant resistance potential to lipid oxidation. This hypothesis seems true since the PI and UI values were lower in the samples from outdoor pigs.

Although phospholipids represent only some $3.6 \%$ of the total lipid content of mechanically deboned pork meat (Kuchmak and Dugan, 1963), they have sensorial and health aspects. In our case, 
based on the reduction in total unsaturation, we suppose potential alterations in the aroma and juiciness of the thigh meat from outdoor animals, as UFAs of phospholipids play an important role in the juiciness and formation of volatile compounds. In an earlier study by Jonsäll et al. (2001), the $m$. biceps femoris ham from outdoor pigs was found to be less juicy, while no alteration was detected in tenderness. On the other hand, AI decreased in outdoor animals due to the high atherogenic agents (myristic and palmitic acids, according to Laudadio and Tufarelli (2010)) and total saturation level, postulating a higher intake of meat from this keeping system may not be considered as healthy for consumers (elevation of cholesterol species are associated with cardiovascular disorders (Won et al., 2020)). However, we suppose a negligible AI effect on consumers, since the TI and $\mathrm{h} / \mathrm{H}$ were not altered and FA composition differences between meat neutral and polar lipids were proven (Högberg et al., 2003; Parunović et al., 2012).

The outdoor population provided an unequivocal excess of $\mathrm{C} 16$ and $\mathrm{C} 18$ MUFAs in the muscle fibre membranes; this led to an absolute $4 \%$ surplus of mono-unsaturation overall. A hassling increment in outdoor muscle MUFA overall was reported by Parunović et al. (2012) and Andrés et al. (2001), in $m$. tibialis cranialis and $m$. biceps femoris, respectively. In contrast, Hoffman et al. (2003) have reported an increase in the total proportion of PUFAs in the complex fat content of $m$. longissimus dorsi from pigs reared in the outdoor system of tropical areas (higher ambient temperatures). According to Lebret (2008), the ratio between MUFA:PUFA may increase in intramuscular fat with the extreme reduction in ambient temperature, although swine is a homoeothermic species. In the whole body volume, fat deposition was lower in the outdoor pigs, postulating less total PUFA level in the polar lipids. Högberg et al. (2003) discovered a negative relationship between total PUFA proportion of triglycerides and phospholipids and carcass fatness. The outdoor environment appears to influence a preferential allocation of monounsaturated FAs into the sarcolemma via a de novo FA-synthetic pathway, selective FA arrangement into different sites, and local remodeling reactions. In our case, those events were based on compromising the total polyunsaturation level ( $9 \%$ lower in outdoor animals), probably increased membrane rigidity and protected against lipid peroxidation. It is well-known that prolonged aerobic exercise is a continuous oxidative stimulus that provokes the adaptation of the cellular antioxidant system. The negative association between the MUFA level in phospholipids and the final thiobarbituric acid reactive substances (TBARs) concentration was documented by Andrés et al. (2001), supporting our proposal.

Linoleic acid (LA) is an essential FA. The decrease in LA in outdoor reared pigs may be explained by two factors: either the low preferred channeling of this FA into the phospholipid fraction or the lower uptake of the LA due to lower feed intake. None of those were proven in this study, while no surplus dietary source was provided (the field was practically pure mud, without vegetation). On the other hand, ALA is also essential for mammals. The significant difference was about $0.1 \%$ absolute proportion, which is of minor physiological importance. Eicosatrienoic acid (C20:3n3) was a minor component, but along the mammalian FA metabolism, this acid is produced on the bypass pathways of $\mathrm{C} 22: 5 \mathrm{n} 3$ and DHA biosynthesizes via a series of desaturases and chain elongation steps (Voss et al., 1991). Thus, it is an essential FA for assessing the elongation/desaturation reactions that convert dietary C18 FAs to C20 eicosanoid precursors. The decrease in eicosatrienoic acid proportion indirectly refers to inhibition of C18 FAs conversion to eicosanoid precursors in the outdoor system. However, the critical important concern might be the DHA produced in six consecutive enzymatic reactions from ALA. The increase in DHA proportion refers to a rather specific adaptation due to its anti-inflammatory characteristics, which enhances muscle protein synthesis and mitochondrial respiration kinetics (McGlory et al., 2019). In growing pigs, DHA supplementation has resulted in high expression of muscle insulin-like growth factor 1 (IGF-1) and activation of the insulin receptor, which has enhanced muscular protein synthesis (Wei et al., 2013). The high presence of this FA indirectly indicates that pigs were undergoing lesser oxidative stress with a proper antioxidant defence.

The arachidonic acid proportion was found to decrease in pigs reared under the outdoor system. Similar findings have been noted in $\mathrm{m}$. tibialis cranialis by Andrés et al. (2001). The proportional decrease of arachidonic and LA resulted from the decrease in total omega-6 FA proportion, consequently, lower the total omega-6:omega-3 ratio (approximately from 21 to 17). The low omega-3:omega-6 ratio has physiological importance since LA and ALA are precursors for omega- 6 and omega-3 long-chain homologs, respectively, and different eicosanoids. It has been proposed that the ratio should not exceed 4-6 in human diet (Wood et al., 2008). A similar decrease 
in the omega ratio has been reported in studies on pigs reared on pasture containing high levels of ALA (Bee et al., 2004; Lebret and Guillard, 2005). In our design, both groups were fed a similar complete diet and no pasture-grazing activity was allowed; thus, the decrease in omega-6:omega- 3 ratio was proven to be independent of roughage supply. However, we are unable to rule out the diet because the feed was offered ad libitum and the groups' intakes were not determined. The other possibility is that outdoor activities and conditions could alter the omega-6:omega-3 ratio to improve cellular muscle metabolism.

\section{Antioxidant enzymes and lipid peroxidation}

It was shown that free-range keeping of animals with no pasturing had no effect on the antioxidant capacity of the plasma as compared to the closed kept group. Many other studies show that the outdoor system enhances the antioxidant capacity of pigs, where these animals have free access to pastures containing forage rich in $\alpha$-tocopherols, vitamins E, A and C (Wood et al., 2008; Martino et al., 2014), or any other antioxidant bioactive compound, i.e. arginine and carnosine (Quinn et al., 1992; Ma et al., 2010). In the present study, the prevention against the development of lipid peroxidation was independent of the dietary antioxidant supplements. We thus suggest that modulation of membrane lipid composition into a more rigid structure that comprises higher proportions of SFAs and MUFAs (less sensitive to lipid peroxidation; decreased PI and UI) was the key mechanism behind our insignificant oxidative stress findings.

From a meat quality perspective, based on the unsaturation level in pork, the risk of generation of lipid oxidation products can be predicted. A consequence of lipid oxidation in meat is the deterioration of flavour and colour qualities. The establishment is that increasing the saturation level in phospholipids of outdoor animals may provide significant resistance to lipid oxidation, extending the shelf-life of the meat. Once animals were not sacrificed in our study, and meat qualities were not determined, additional research is required to reveal the relationship between the phospholipid FA profile and meat qualities.

\section{Conclusions}

A modern pig genotype is viable to be raised in an outdoor keeping system, whereas a slight fallback occurred in the growth rate. Outdoor housing altered the body trait parameters of the total body volume; as higher muscle (\%) and lower fat (\%) were stated. Those modifications may refer to more lean meat produced by outdoor animals. The outdoor system could alter the skeletal muscle bilayer. Higher contents of saturated fatty acids (SFA) and monounsaturated fatty acids (MUFA) have compromised the total polyunsaturated fatty acids (PUFA) proportion, referring to rigid muscle fibre membranes, proposed to protect against oxidation (low unsaturation index and peroxidation index). The protection against lipid peroxidation is likely to increase the meat's shelflife. The omega-6:omega-3 ratio was decreased in phospholipids, suggesting an anti-inflammatory effect. Thus, outdoor rearing may provide healthier dietary pork for consumers. However, the choice of housing system highly relies on market demands. Therefore, further investigations are necessary to associate pork qualities with housing design.

\section{Acknowledgements}

The publication is supported by the János Bolyai Research Scholarship of the Hungarian Academy of Sciences (BO/00871/19). This research was partly funded by the Ministry of Human Resources (EFOP-3.6.3-VEKOP-16-2017-00008).

\section{Conflict of interest}

The authors declare that there is no conflict of interest.

\section{References}

Andrés A.I., Cava R., Mayoral A.I., Tejeda J.F., Morcuende D., Ruiz J., 2001. Oxidative stability and fatty acid composition of pig muscles as affected by rearing system, crossbreeding and metabolic type of muscle fibre. Meat Sci. 59, 39-47, https:// doi.org/10.1016/s0309-1740(01)00050-x

Andresen N., Ciszuk P., Ohlander L., 2001. Pigs on grassland: animal growth rate, tillage work and effects in the following winter wheat crop. Biol. Agric. Hortic. 18, 327-343, https://doi.org/10 1080/01448765.2001.9754896

Beattie V.E., O'Connell N.E., Moss B.W., 2000. Influence of environmental enrichment on the behaviour, performance and meat quality of domestic pigs. Livest. Prod. Sci. 65, 71-79, https://doi.org/10.1016/S0301-6226(99)00179-7

Bee G., Guex G., Herzog W., 2004. Free-range rearing of pigs during the winter: Adaptations in muscle fiber characteristics and effects on adipose tissue composition and meat quality traits. J. Anim. Sci. 82, 1206-1218, https://doi.org/10.2527/2004.8241206x

Botsoglou N.A., Fletouris D.J., Papageorgiou G.E., Vassilopoulos V.N., Mantis A.J., Trakatellis A.G., 1994. Rapid, sensitive and specific thiobarbituric acid method for measuring lipid peroxidation in animal tissue, food and feedstuff samples. J. Agric. Food Chem. 42, 1931-1937, https://doi.org/10.1021/ jf00045a019 
Bunter K.L., Bennett C., Luxford B.G., Graser H.-U., 2008. Sire breed comparisons for meat and eating quality traits in Australian pig populations. Animal 2, 1168-1177, https://doi.org/10.1017/ S1751731108002085

Christie W.W., 1982. A simple procedure for rapid transmethylation of glycerolipids and cholesteryl esters. J. Lipid Res. 23, 10721075, https://doi.org/10.1016/S0022-2275(20)38081-0

Dostálová A., Svitáková A., Bureš D., Vališ L., Volek Z., 2020. Effect of an outdoor access system on the growth performance, carcass characteristics, and longissimus lumborum muscle meat quality of the Prestice Black-Pied pig breed. Animals 10, 1244, https://doi.org/10.3390/ani10081244

Enfält A.-C., Lundström K., Hansson I., Lundeheim N., Nyström P.E., 1997. Effects of outdoor rearing and sire breed (Duroc or Yorkshire) on carcass composition and sensory and technological meat quality. Meat Sci. 45, 1-15, https://doi. org/10.1016/s0309-1740(96)00101-5

Fernández M., Ordóñez J.A., Cambero I., Santos C., Pin C., de la Hoz L., 2007. Fatty acid compositions of selected varieties of Spanish dry ham related to their nutritional implications. Food Chem. 101, 107-112, https://doi. org/10.1016/j.foodchem.2006.01.006

Folch J., Lees M., Sloane Stanley G.H., 1957. A simple method for the isolation and purification of total lipides from animal tissues. J. Biol. Chem. 226, 497-509, https://doi.org/10.1016/S00219258(18)64849-5

Gentry J.G., McGlone J.J., Miller M.F., Blanton J.R., 2004. Environmental effects on pig performance, meat quality, and muscle characteristics. J. Anim. Sci. 82, 209-217, https://doi. org/10.2527/2004.821209x

Gustafson G.M., Stern S., 2003. Two strategies for meeting energy demands of growing pigs at pasture. Livest. Prod. Sci. 80, 167-174, https://doi.org/10.1016/S0301-6226(02)00319-6

Guy J., Rowlinson P., Chadwick J., Ellis M., 2002. Growth performance and carcass characteristics of two genotypes of growingfinishing pig in three different housing systems. Anim. Sci. 74, 493-502, https://doi.org/10.1017/S1357729800052656

Hoffman L.C., Styger E., Muller M., Brand T.S., 2003. The growth and carcass and meat characteristics of pigs raised in a freerange or conventional housing system. S. Afr. J. Anim. Sci. 33, 166-175, https://doi.org/10.4314/sajas.v33i3.3770

Högberg A., Pickova J., Andersson K., Lundström K., 2003. Fatty acid composition and tocopherol content of muscle in pigs fed organic and conventional feed with different n6/n3 ratios, respectively. Food Chem. 80, 177-186, https://doi. org/10.1016/s0308-8146(02)00252-2

Hung C., Bronec C., Napoli E., Graham J., Stanhope K.L., Marsilio I., Giron M.C., Havel P.J., Giulivi C., 2018. Adipose depot-specific effects of ileal interposition surgery in UCD-T2D rats: unexpected implications for obesity and diabetes. Biochem. J. 475, 649-662, https://doi.org/10.1042/ BCJ20170899

Jonsäll A., Johansson L., Lundström K., 2001. Sensory quality and cooking loss of ham muscle (M. biceps femoris) from pigs reared indoors and outdoors. Meat Sci. 57, 245-250, https:// doi.org/10.1016/s0309-1740(00)00097-8

Juska R., Juskiene V., Leikus R., 2013. The influence of a free-range housing system on pig growth, carcass composition and meat quality. J. Appl. Anim. Res. 41, 39-47, https://doi.org/10.1080 109712119.2012.738215

Karpiesiuk K., Falkowski J., 2008. Reaction of fatteners to different management conditions. Rocz. Nauk. PTZ 4, 65-75, http:// ptz.icm.edu.pl/download/2008/tom_4_4/7_Karpiesiuk.pdf (accessed on July 25, 2021)
Kozera W., Karpiesiuk K., Bugnacka D., Falkowski J., Milewska W. 2016. Production performance of pigs reared in different systems and fed increased energy content diets with or without green alfalfa. S. Afr. J. Anim. Sci. 46, 70-76, https:// doi.org/10.4314/sajas.v46i1.9

Kuchmak M., Dugan L.R., 1963. Phospholipids of pork muscle tissues. J. Am. Oil Chem. Soc. 40, 734-736, https://doi.org/10.1007/ BF02609657

Laudadio V., Tufarelli V., 2010. Influence of substituting dietary soybean meal for dehulled-micronized lupin (Lupinus albus cv. Multitalia) on early phase laying hens production and egg quality. Livest. Sci. 140, 184-188, https://doi.org/10.1016/j. livsci.2011.03.029

Lawrence R.A., Burk R.F., 1978. Species, tissue and subcellular distribution of non Se-dependent glutathione peroxidase activity. J. Nutr. 108, 211-215, https://doi.org/10.1093/ jn/108.2.211

Lebret B., 2008. Effects of feeding and rearing systems on growth, carcass composition and meat quality in pigs. Animal 2 , 1548-1558, https://doi.org/10.1017/S1751731108002796

Lebret B., Dourmad J.Y., Mourot J., Pollet P.Y., Gondret F., 2014. Production performance, carcass composition, and adipose tissue traits of heavy pigs: Influence of breed and production system. J. Anim. Sci. 92, 3543-3556, https://doi.org/10.2527/ jas.2013-7398

Lebret B., Guillard A.-S., 2005. Outdoor rearing of cull sows: effects on carcass, tissue composition and meat quality. Meat Sci. 70, 247-257, https://doi.org/10.1016/j.meatsci.2005.01.007

Lemke U., Mergenthaler M., Rössler R., Huyen L.T.T., Herold P., Kaufmann B., Zárate A.V., 2008. Pig production in Vietnam a review. CAB Rev. Perspect. Agric. Vet. Sci. Nutr. Nat. Resour. 3, 023, https://doi.org/10.1079/PAVSNNR20083023

Leray C., Andriamampandry M., Gutbier G., Cavadenti J., Klein-Soyer C., Gachet C., Cazenave J.P., 1997. Quantitative analysis of vitamin $\mathrm{E}$, cholesterol and phospholipid fatty acids in a single aliquot of human platelets and cultured endothelial cells. J. Chromatogr. B Biomed. Sci. Appl. 696, 33-42, https://doi. org/10.1016/s0378-4347(97)00230-2

Ma X., Lin Y., Jiang Z., Zheng C., Zhou G., Yu D., Cao T., Wang J., Chen F., 2010. Dietary arginine supplementation enhances antioxidative capacity and improves meat quality of finishing pigs. Amino Acids 38, 95-102, https://doi.org/10.1007/ s00726-008-0213-8

Maribo H., Nielsen B., Friis Nielsen M.B., 2018. Danbred Duroc crossbred finishers grow faster than Pietrain crossbreds. SEGES Danish Pig Res. Cent. 1-10, https:// pigresearchcentre.dk/-/media/PDF/English-site/Research_ PDF/Finishers/Meddelelse_1154_UK.ashx (accessed on April 23, 2021)

Martínez-Miró S., Tecles F., Ramón M., Escribano D., Hernández F., Madrid J., Orengo J., Martínez-Subiela S., Manteca X., Cerón J.J., 2016. Causes, consequences and biomarkers of stress in swine: an update. BMC Vet. Res. 12, 171, https:// doi.org/10.1186/s12917-016-0791-8

Martino G., Mugnai C., Compagnone D., Grotta L., Del Carlo M., Sarti F., 2014. Comparison of performance, meat lipids and oxidative status of pigs from commercial breed and organic crossbreed. Animals 4, 348-360, https://doi.org/10.3390/ ani4020348

McGlory C., Calder P.C., Nunes E.A., 2019. The influence of omega-3 fatty acids on skeletal muscle protein turnover in health, disuse, and disease. Front. Nutr. 6, 144, https://doi. org/10.3389/fnut.2019.00144 
Nilzén V., Babol J., Dutta P.C., Lundeheim N., Enfält A.-C., Lundström K.., 2001. Free range rearing of pigs with access to pasture grazing - effect on fatty acid composition and lipid oxidation products. Meat Sci. 58, 267-275, https://doi.org/10.1016/ s0309-1740(00)00164-9

Olsson V., Andersson K., Hansson I., Lundström K., 2003. Differences in meat quality between organically and conventionally produced pigs. Meat Sci. 64, 287-297, https://doi. org/10.1016/S0309-1740(02)00200-0

Parunović N., Petrović M., Matekalo-Sverak V., Trbović D., Mijatović M., Radović C., 2012. Fatty acid profile and cholesterol content of $m$. longissimus of free-range and conventionally reared Mangalitsa pigs. S. Afr. J. Anim. Sci. 42, 101-113, http://www. scielo.org.za/pdf/sajas/v42n2/02.pdf (accessed on April 23, 2021)

Patton B.S., Huff-Lonergan E., Honeyman M.S., Crouse J.D., Kerr B.J., Lonergan S.M., 2008. Effects of deep-bedded finishing system on market pig performance, composition and pork quality. Animal 2, 459-470, https://doi.org/10.1017/ S1751731107001292

Quinn P.J., Boldyrev A.A., Formazuyk V.E., 1992. Carnosine: Its properties, functions and potential therapeutic applications. Mol. Asp. Med. 13, 379-444, https://doi.org/10.1016/00982997(92)90006-I

Rahman I., Kode A., Biswas S.K., 2006. Assay for quantitative determination of glutathione and glutathione disulfide levels using enzymatic recycling method. Nat. Protoc. 1, 3159-3165, https://doi.org/10.1038/nprot.2006.378

Rioux V., 2016. Fatty acid acylation of proteins: specific roles for palmitic, myristic and caprylic acids. OCL 23, D304, https:// doi.org/10.1051/ocl/2015070

Sather A.P., Jones S.D.M., Schaefer A.L., Colyn J., Robertson W.M., 1997. Feedlot performance, carcass composition and meat quality of free-range reared pigs. Can. J. Anim. Sci. 77, 225-232, https://doi.org/10.4141/A96-093

Skjervold H., Grønseth K., Vangen O., Evensen A., 1981. In vivo estimation of body composition by computerized tomography. Z. Tierzüchtg. Züchtgsbiol. 98, 77-79, https:// doi.org/10.1111/j.1439-0388.1981.tb00330.x

Strudsholm K., Hermansen J.E., 2005. Performance and carcass quality of fully or partly outdoor reared pigs in organic production. Livest. Prod. Sci. 96, 261-268, https://doi. org/10.1016/j.livprodsci.2005.02.008

Tomažin U., Batorek-Lukač N., Škrlep M., Prevolnik-Povše M., Čandek-Potokar M., 2019. Meat and fat quality of Krškopolje pigs reared in conventional and organic production systems. Animal 13, 1103-1110, https://doi.org/10.1017/ S1751731118002409
Ulbricht T.L.V., Southgate D.A.T., 1991. Coronary heart disease: seven dietary factors. Lancet 338, 985-992, https://doi. org/10.1016/0140-6736(91)91846-m

Urbańczyk J., Hanczakowska E., Światkiewicz M., 2005. The effect of organic feeding on carcass and meat quality of fattening pigs. J. Anim. Feed Sci. 14, Suppl. 1, 409-412, https://doi. org/10.22358/jafs/70592/2005

Voss A., Reinhart M., Sankarappa S., Sprecher H., 1991. The metabolism of 7,10,13,16,19-docosapentaenoic acid to $4,7,10,13,16,19$-docosahexaenoic acid in rat liver is independent of a 4-desaturase. J. Biol. Chem. 266, 19995-20000, https://doi.org/10.1016/S0021-9258(18)54882-1

Wei H.K., Zhou Y., Jiang S., Tao Y.X., Sun H., Peng J., Jiang S., 2013. Feeding a DHA-enriched diet increases skeletal muscle protein synthesis in growing pigs: association with increased skeletal muscle insulin action and local mRNA expression of insulin-like growth factor 1. Br. J. Nutr. 110, 671-680, https:// doi.org/10.1017/S0007114512005740

Weichselbaum C.T.E., 1946. An accurate and rapid method for the determination of proteins in small amounts of blood serum and plasma. Am. J. Clin. Pathol. 16, 40-49, https://doi. org/10.1093/ajcp/16.3_ts.40

White H.M., Richert B.T., Latour M.A., 2013. Impacts of nutrition and environmental stressors on lipid metabolism. In: R.V. Baez (Editor). Lipid Metabolism. IntechOpen, London (UK), pp. 211-232, https://doi.org/10.5772/51204

Won K.B., Han D., Lee J.H., Choi S., Chun E.J., Park S.H., Han H.W., Sung J., Jung H.O., Chang H.J., 2020. Atherogenic index of plasma and coronary artery calcification progression beyond traditional risk factors according to baseline coronary artery calcium score. Sci. Rep. 10, 21324, https://doi.org/10.1038/ s41598-020-78350-x

Wood J.D., Enser M., Fisher A.V., Nute G.R., Sheard P.R., Richardson R.I., Hughes S.I., Whittington F.M., 2008. Fat deposition, fatty acid composition and meat quality: a review. Meat Sci. 78, 343-358, https://doi.org/10.1016/j. meatsci.2007.07.019

Zhang S., Knight T.J., Stalder K.J., Goodwin R.N., Lonergan S.M., Beitz D.C., 2009. Effects of breed, sex and halothane genotype on fatty acid composition of triacylglycerols and phospholipids in pork longissimus muscle. J. Anim. Breed. Genet. 126, 259-268, https://doi.org/10.1111/j.1439-0388.2008.00782.x 